\title{
TRADICIÓNS REINTERPRETADAS E INVENTADAS : OS GRUPOS ÉTNICOS DE EUROPA E O PAPEL DO FOLKLORE NA CONSTRUCCIÓN DAS SÚAS IDENTIDADES*
}

\author{
Por \\ XOSÉ MANUEL GONZÁLEZ REBOREDO
}

\section{CONCEPTOS E DELIMITACIÓNS INICIAIS}

Os traballos antropolóxicos dedicados á identidade étnica ou etnonacional utilizan uns conceptos que é preciso chamar a capítulo antes de entrar na temática central desta exposición.

En xeral os conceptos que imos manexar derivan todos da palabra grega éthnos, que orixinariamente se utilizaba para aludir a grupos de persoas e animais que comparten algunhas catacterísticas culturais ou biolóxicas e que viven e actúan conxuntamente. Sófocles utilízaa para os animais salvaxes, pero Píndaro para definir os grupos humanos distintos dos gregos. Cando pensadores coma Aristóteles a aplicaban a colectividades humanas, sempre estaba referida ó «outro», é dicir ó estranxeiro. Se os outros eran considerados ethnea, é dicir, étnicos, os gregos, polo contrario, auto-

* Este texto, con adaptacións a cada circunstancia concreta, serviu de base para conferencias pronunciadas en Lugo, con motivo dos actos do cincuentenario de «Cantigas e Frores», en Ortigueira, no acto de entega dos premios David Foxo de 1998, e tamén nun acto organizado polo Clube Nacionalista Alén Nós en Compostela. Queremos, por outra banda, agradecer ó profesor Xosé Chao Rego a xentileza que tivo de leer esta definitiva redacción e suxerir correccións que a melloraron notoriamente.

"CUADERNOS DE ESTUdios GALLEGOS", Tomo XLVII, Fascículo 112, Santiago 2000. 
definíanse como génos Hellenon. Con posterioridade, xa na Grecia cristiá, o vocábulo éthne, en plural, chegou a significar «xentís» ou «pagáns» Pola súa banda, os romanos identificábanse como populus e para os foráneos reservaban o termo natio, do que derivan as verbas nación, nacionalismo, etc. (TONKIN, McDONALD, CHAPMAN, 1996:18).

A partir do étimo grego xurdiron na literatura antropolóxica termos como o francés de ethnie e o hispano de etnia, que no seu uso científico xenérico remiten a un colectivo con trazos propios de lingua, cultura ou territorio (BONTÉ e IZARD, voz «etnia»). Se etnia é vocábulo francés de berce, no mundo anglosaxón utilízanse outros derivados, moitas veces en forma adxectiva; así, os antropólogos de fala inglesa soen aludir nos seus escritos a ethnic group, ethnic community, ou, o que é máis común, ó concepto de ethnicity, establecendo a etnicidade coma un atributo propio de colectividades humanas. Seguindo a Hutchinson e Smith (HUTCHINSON e SMITH, 1996: 6) podemos definir unha etnia ou comunidade étnica coma un conxunto humano con mitos de oríxe comúns, memoria histórica compartida, un ou varios elementos de cultura común (incluída a lingua e os costumes en moitos casos, e a relixión noutros), unha vinculación a un territorio e un certo sentido de solidariedade entre os seus membros. É de advertir que poden existir grupos humanos nos que algún destes compoñentes teñan escasa ou nula importancia, pero en calquera caso a posesión dalgún deles abonda para establecer as diferencias étnicas. Un destes compoñentes, a raza, entendida coma trazos fenotípicos externos, non ten decisiva importancia en canto a elemento diferenciador entre etnias, por moito que na nosa mentalidade xeral aínda perviva unha íntima asociación entre raza e etnia, en grande medida superada ou matizada nos escritos dos antropólogos. Con todo, por veces o aspecto físico pode ser utilizado polos alleos para establecer unha inicial catalogación dun grupo étnico ( (os xitanos son morenos», por exemplo).

O conxunto de trazos lingüísticos, culturais, a relación específica do grupo cun territorio e só en certa medida ou ocasión os trazos raciais serven para construír o que se vén chamando o imaxinario étnico dun grupo (AGUIRRE, 1993: entrada «imaxinario étnico»).O feito de pertencer a unha etnia ou grupo étnico xera unha identidade baseada neste específico imaxinario Esta identidade pode ser definida, seguindo a A. Aguirre, coma o sistema cultural de referencia dunha comunidade humana ou como un conxunto de indicadores culturais que outorgan a esa comunidade unha 
identidade no contexto social (AGUIRRE, 1993: entrada «identidad étnica»). Non imos deternos en expoñer as relacións entre identidade persoal e identidade socio-cultural, mais si é necesario destacar que o conxunto de elementos culturais compartidos inciden nos individuos e xeran identidades grupais das que a identidade étnica é una variante. Efectivamente, nas sociedades complexas os individuos contan cun grande cúmulo de referentes dos que botar man para autodefinirse; así, poderiamos falar no mundo capitalista dunha identidade de clase, e mesmo de identidades xeradas pola profesión ou pola actividade desenvolvida, utilizando cada individuo estas identidades en función das circunstancias (eu podo identificarme coma «galego» e con iso manifesto a miña identidade étnica; pero tamén coma «profesor» ou «investigador», co que estou salientando a miña identidade profesional). Precisamente nas sociedades complexas, formadas por distintas clases sociais, diferentes colectivos profesionais e varios grupos étnicos, pode darse o caso de que se produza un certo solapamento entre a identidade de clase e a identidade étnica, o que levou ó investigador norteamericano Milton M. Gordon a cuñar o concepto de etclase para englobar as relacións entre clase e etnia (AGUIRRE, 1993: entrada "etclase»). Dende esta perspectiva, os «lombos mollados» mexicanos que penetran nos EEUU, ou os marroquinos que cruzan o Estreito de Xibraltar, son tanto un grupo étnico como unha clase social subproletaria nos países de acollida.

O concepto de etclase utilízase como ferramenta de análise cando se dirixe a ollada do investigador ás sociedades complexas contemporáneas nas que conviven xentes de distinta oríxe étnica e diferente status social. Seguramente o noso mundo camiña cara a esa complexidade a gran velocidade (resultaría estraño para un francés de hai medio século ter que admitir que hoxe no seu país os musulmáns practicantes son o segundo colectivo relixioso de Francia, tralos católicos). Pero, por razóns de tempo, deixaremos de lado a problemática das sociedades multiétnicas e ímos abordar as etnias e a identidade étnica dende un posicionamento máis clásico, considerando os colectivos ós que aludiremos como conxuntos mínimamente uniformes.

O estudio da identidade étnica conta nos últimos decenios con dúas perspectivas que imos resumir.

A) Por unha banda temos a interpretación que adoita denominarse primordialista. Entre os máis importantes representantes do primordialismo 
está o antropólogo norteamericano C. Geertz, quen considera que existen uns lazos primordiais que son os que unen ós membros dun mesmo grupo étnico. Estes lazos non son algo que se poida racionalizar previamente, senón feitos «dados», previos a calquera racionalización. A contigüidade inmediata e as conexións de parentesco, o nacer nunha comunidade relixiosa determinada, o falar unha lingua ou dialecto desta lingua, o manter uns costumes propios, ou o sentirse vencellados a un territorio concreto, son igualdades que se vivencian coma vínculos «inefables, vigorosos e obrigatorios en si mesmos» (C. GEERTZ, 1988: 222), debidos máis a unha afinidade espiritual ou natural que á interacción social. As agresións contra estes primordialismos poden dar lugar a respostas moi diversas, algunhas por desgracia enormementes violentas, inspiradas máis na afectividade que na racionalidade. O descontento primordial é máis fondo que outros descontentos e resulta máis difícil de resolver: os revolucionarios parisinos do século XVIII, movidos polo civismo, pediron a cabeza de Luís XVI; pero o que pediron e piden moitos dos movementos separatistas da exUnión Soviética, ou da ex-Iugoslavia, é a cabeza do Estado preexistente.

A interpretación primordialista, que se centra en detectar elementos indiscutibles e estáticos da identidade étnica, destaca un aspecto das sociedades humanas que poderiamos definir como a «communitas». En todas partes os seres humanos desenvolveron unha mentalidade social que se move entre dous polos, un representado pola citada "communitas», referente de afectividade, e outro, a «societas», froito da racionalidade. A primeira achéganos ó polo da identidade étnica, mentres que a segunda faino en dirección ó da identidade cívica. Como teñen sinalado algúns investigadores do tema, o modelo francés de cidadanía elaborado a partir dos principios do racionalismo ilustrado postos en práctica pola Revolución Francesa produciu a construcción do Estado contemporáneo, da «societas», pero o modelo alemán, cuñado á sombra do sentimentalismo romántico, condúcenos á idea de nación coma «communitas», unha nación na que non só o «ius solis», senón tamén o «ius sanguinis» teñen un peso importante (PUJADAS, 1993: 77). A duplicidade de «communitas / «societas» foi xa destacada por sociólogos de finais do século XIX, como o alemán Tönnies, que publicou en 1887 un libro precisamente titulado Gemeinschaft und Gesellschaft (comunidade e sociedade). Segundo a súa formulación, a comunidade é orgánica e a sociedade mecánica; a primeira establece relacións afectivas primordiais, mentres que a sociedade ten fi- 
nalidades concretas, materiais; as formas comunitarias son «naturais», nacen do sangue común, do lugar común, do espírito común; a sociedade é «artificial» e constitúese en institucións coma partidos, sindicatos ou asociacións. Na sociedade os individuos son situados por riba de todo, mentres a comunidade os integra nun grupo transcendente (TÖNNIES, 1979: 27 e ss.). Curiosamente, un antropólogo anglosaxón, V. Turner, especialista en simbolismo e ritual, reelaborou o concepto de «communitas», contrapoñéndoo ó de «estructura»e demostrando que en certas circunstancias reverdece a «communitas» dentro da estructura (TURNER, 1993: 517 e ss.). Sen saír de Galicia, algunhas das nosas festas tradicionais parecen apuntar a unha construcción festivo-simbólica dunha «communitas» porque supoñen unha abolición momentánea da estructura social e permiten a liberación de actitudes ou a adopción de roles pouco probables na vida diaria; na medida en que son «festas de todos» e non só «festas para todos», representan esa dimensión comunitaria da que estamos a falar (VELASCO, CRUCES e DÍAZ, 1996: 147). En calquera caso, «communitas» e «societas» conviven ou alternan nos grupos humanos, $\mathrm{e}$ soamente un equilibrio máis ou menos estable entre os dous aspectos das sociedades e dos individuos permite unha coexistencia pacífica. A maior parte dos conflictos étnicos que se producen no noso mundo soen ocultar algún tipo de disonancia entre a comunidade e a sociedade, representada polo Estado.

B) Fronte ó primordialismo antes citado, hai outra corrente de interpretación das identidades étnicas que podemos denominar situacionalista, ou interaccionalista, consolidada cos estudios do noruegués Barth. Para Barth a identidade étnica non é algo estático, algo baseado nunha serie de elementos que permanecen inamovibles. Segundo el as etnias están en permanente interacción cos «outros», o que obriga a continuas redefinicións, reinterpretacións ou recreacións desa identidade. A comprensión da identidade étnica esixe, dende esta perspectiva, distanciarse do núcleo dos lazos primordiais e achegarse ás fronteiras da etnicidade -non ás fronteiras físicas, senón sobre todo ás fronteiras conceptuais ou culturais-(BARTH, 1976: 17 e ss). A identidade dos lapóns das costas de Finmarken, por exemplo, maniféstase dun xeito determinado en función do contacto cos noruegueses dominantes, o que provoca a aparición de estratexias de disimulo e de ocultación pública desa identidade en función dunha interacción asimétrica (EIDHEIM, 1976: 50 e ss.)

"CUADERNOS DE eStUdios GALLEGOS", Tomo XLVII, Fascículo 112, Santiago 2000. 
As dúas teorías da identidade étnica poden ser consideradas coma complementarias, aínda que conduzan a interpretacións diferentes. De tódolos xeitos non é este o lugar para esterdérmonos máis sobre o asunto. Soamente advertiremos que en adiante usaremos frecuentemente exemplos illados que poden ser considerados coma feitos primordiais, sen prexuízo de que amosemos as súas ás veces sorprendentes adaptacións, froito da interacción cos outros. Porque hai que aceptar que a identidade étnica non ten sentido se non existe un «outro» con quen contrastarse, de quen defenderse ou con quen colaborar. Á fin e ó cabo un non é galego, lapón, bretón ou escocés se non existen «outros». Eles serven de contrapunto da nosa identidade, axúdannos a definir as nosas fronteiras étnicas mediante o que din ou pensan de nosoutros, e establecen unhas relacións variadas connosco. Como di Alan Dundes, non hai un «eu» sen o «outro», non hai unha identidade grupal A sen, polo menos, un grupo B de contraste/interacción (DUNDES, 1983: 238).

\section{GRUPOS ÉTNICOS E NACIONALISMO EN EUROPA}

A finais dos anos setenta, dous investigadores, Jaroslav Krejci y Vitézlav Velímský, elaboraron unha relación dos grupos étnicos en Europa que ten diversos defectos, pero que en xeral é unha inicial enumeración das etnias da vella Europa. (KREJCI e VELÍMSKÝ, 1996: 209 e ss.). Entre os Urais e o Atlántico lograron detectar un total de 73 grupos étnicos, dos que 15 se corresponden coas terras do occidente europeo. Dentro destas 15 etnias, na Península Ibérica conviven cinco, denominadas polos citados investigadores como Vascos, Cataláns, Españois, Galegos e Portugueses. A eles poderiamos sumar os xitanos, grupo étnico que se caracteríza por carecer dun territorio definido de referencia. Os criterios seguidos para delimitar un grupo étnico foron:

- Posesión dun territorio definido.

- Estatus político (soberanía plena, autonomía, carencia de estatus político)

- Historia política propia (ou carencia da mesma)

- Cultura (en sentido amplo, incluindo, por exemplo, a relixión).

- Lingua (ou dialecto)

"CUADERNOS DE ESTUdIOS GALLEGOS", Tomo XLVII, Fascículo 112, Santiago 2000. 
- Conciencia de identidade étnica, política ou ámbalas dúas. - Poboación.

Deixando de lado a poboación, que é unha cuestión meramente estatística, os demais elementos combínanse de diversa maneira nos distintos grupos étnicos, e resulta case imposible atopar un que teña unha diferenciación clara en tódolos items. Así, hai 5 etnias occidentais que posúen un Estado propio, mentres as demáis están englobadas nalgún dos Estados anteriores, tendo algún tipo de autonomía outras seis (eles non inclúen Galicia neste apartado porque cando redactaron o seu traballo aínda non estaba funcionando o Estado das Autonomías, pero nós si o fixemos) e carecendo as catro restantes dalgún tipo de recoñecemento político. No que se refire á lingua, hai etnias con lingua propia, pero outras comparten outra lingua. Hai, con todo, dous items que todos cumpren (agás os citados xitanos), que son a posesión dun territorio delimitado e dunha conciencia étnica que en casos está acompañada de conciencia política. En xeral, as delimitacións que nos facilita este estudio, aínda que incompletas, amosan que as tendencias uniformadoras dos Estados contemporáneos non foron capaces de acabar cunhas identidades que se apoian en elementos que podemos cualificar de étnicos en orixe. Nunha Europa que tende á unidade e nun mundo que tende á globalización dos fenómenos económicos, sociais e culturais, semella que os grupos étnicos son capaces de sobrevivir mantendo algúns referentes de identidade propios.

Esa necesidade diferenciadora foi potenciada e aproveitada dende o século XIX por unha dimensión política que se coñece co nome de nacionalismo, ou, en versión máis atenuada, co de rexionalismo. Á fin e remate, do lado dos nacionalismos que se basean principalmente no civismo, como pode ser o francés desenvolvido a partir da Revolución de 1789, xorden moitos outros coa proxección da identidade étnica nun Estado e supoñen un esforzo por fusionar a política estatal con trazos de identidades preexistentes. Nesta dimensión, o nacionalismo é unha necesidade do mundo contemporáneo que integra elementos da etnicidade en proxectos políticos relacionados co Estado. Por moito que se lle queiran buscar antecedentes, o Estado como hoxe o concibimos é unha creación moi recente, dos dous últimos séculos, e o nacionalismo é unha ideoloxía que se apropia das culturas previas para construír unha teoría política que permi- 
ta a conquista do poder ou dunha parte das competencias dun Estado; o nacionalismo, en suma, como dí Gellner, é froito da civilización moderna, desenvolvida, que aproveita, adaptándoas ás novas circunstancias, formas de cultura antecedentes (GELLNER, 1997: 69). Non tódolos grupos étnicos acabaron converténdose en grupos nacionais; un exemplo extremo, pero ilustrativo, pode ser o dos citados xitanos, unha comunidade ben definida que, sen embargo, non desenvolveu un nacionalismo propio (quizais porque careceu dun soporte territorial axeitado). Pero si é evidente que no seo de moitos grupos étnicos de Europa xurdiron movementos que crearon nacións a partir de elementos da identidade étnica, ou mesmo completaron unha identidade étnica mediante invencións da tradición. $\mathrm{O}$ investigador noruegués Eriksen dános unha mostra deste proceso nun Estado que hoxe todos consideramos coma plenamente consolidado, pero que ten unha historia propia moi curta, dende 1905, tras estar baixo control de Dinamarca dende o século XIV ata 1814 e logo vencellado á coroa sueca, aínda que con parlamento e institucións propias (ERIKSEN, 1993: 101 e ss). En efecto, o nacionalismo noruegués xurdiu no século XIX aproveitando compoñentes dunha teoría tradicionalista que logrou recodificar vellas tradicións ata convertelas en tradicións nacionais. En Noruega son as clases burguesas as que comezan a mirar para os vales remotos en procura da que eles consideraban a «auténtica cultura norueguesa», trasladando trazos illados á cidade e amosándoos como unha expresión de norueguidade. Traxes folklóricos, decoracións florais, melodías recollidas dos campesiños e mesmo pratos da culinaria rural foron elevados á categoría de símbolos de identidade nacional. Resulta importante resaltar que son precisamente xentes procedentes dunha cultura urbana bastante uniforme (un burgués de Oslo pouco se diferenciaba en canto a estilo de vida dos seus homólogos de Estocolmo) as que botan man de formas dunha cultura campesiña en vías de disolución para recompoñer unha identidade ameazada polos cambios producidos pola industrialización. Se destacamos este feito é porque se trata dun fenómeno estendido por toda Europa. Tamén os alemáns decemonónicos, amparados baixo o concepto de nación elaborado polo pensamento protorromántico e romántico, irán construíndo unha identidade nacional alemana a base de sumar compoñentes tomados da tradición popular, especialmente a campesiña. Os esforzos de Herder para demostrar que o pobo é o medio para comezar unha cura de rexuvenecemento da nación non estaban inspirados nas masas 
anónimas das cidades, senón nese pobo que, segundo o seu pensamento, ten unha alma propia porque é capaz de crear, por exemplo, cancións populares. O labor de estudiosos coma Jacob Grimm na recomposición dunha mitoloxía popular xermana serán ampliados, matizados e reorientados con aportacións dun positivismo incrustado na tradición romántica anterior. A Volkskunde, ou Folklore alemán, acabará resultando nunha ciencia conservadora da man de teorías coma as defendidas por Wilhelm Heinrich Riehl no século XIX, unha ciencia ó servicio do nacionalismo, mentres a Etnoloxía, a Völkerskunde, se orientaba ó estudio dos outros pobos (BAUSINGER,1993: 7 e ss). En suma, as culturas industriais enxálzanse mediante, por exemplo, a música e a danza que toman das culturas populares preexistentes, ás que, inxenua, mais necesariamente, pensan que están perpetuando (GELLNER, 1997: 83).

Por primeira vez nesta exposición aparece aludido o folklore nas liñas anteriores. A esta cuestión imos dedicar a parte central dun discurso no que considerei preciso facer esas xa amplas consideracións anteriores co fin de enmarcar o folklore e o folklorismo nun contexto máis amplo. Efectivamente, un elemento secundario que ten importancia á hora de delimitar a identidade étnica dun pobo é o corpus de costumes, festas, música, literatura oral e crenzas que este posúe. Non vou aquí detallar a oríxe e contidos do Folklore, nin tampouco falar sobre a súa inclusión dentro das ciencias antropolóxicas, algo do que me ocupei hai anos (GONZÁLEZ REBOREDO, s./a.: voz «folklore»). Baste lembrar que o Folklore coma póla do saber aparece precisamente á sombra dun romanticismo e postromanticismo propio dunha sociedade burguesa que, como antes vimos co exemplo noruegués, mira cara a ruralía para atopar restos dun pasado periclitado ou en vías de desaparición. E este pasado foi instrumentalizado coma medio de afirmación étnica ou nacional, convertendose así en folklorismo. Segundo dí o investigador Josep Martí, «unha boa parte das diversas manifestacións da cultura tradicional, de ser expoñente dun xeito de vivir, pasou a ser instrumento da nova sociedade de tipo urbano, asignándoselle uns usos estéticos, comerciais e sobre todo ideolóxicos» (MARTí, 1996:11).

Efectivamente, as tradicións incluídas dentro do concepto de folklore en sentido amplo (literatura oral, crenzas, festas, música, traxe, etc.) foron elevadas nos distintos países da vella Europa á categoría de símbolos de identidade. Arrincadas do pobo e situadas no novo contexto da sociedade 
urbano-industrial, van cobrar esta nova dimensión e a pervivir gracias a ela, precisamente nuns tempos nos que os labregos, mariñeiros e artesáns estaban camiño de abandonalas. Ademais, este proceso levouse a cabo seleccionando certos compoñentes da cultura tradicional, que foron trasladados do sistema cultural de orixe para situalos nun novo espacio de significado e trocalos en indicadores dunha cultura diferenciada. A estratexia é habitual nestes métodos de construcción da identidade, pois, como indica o profesor Esteva Fabregat, a etnicidade é un xeito de ser un cunha cultura ó se comparar con xentes de outras culturas (ESTEVA FABREGAT, 1984: 29). Nesta tarefa de construír emblemas ou símbolos prodúcense continuamente reinterpretacións, reubicacións e mesmo invencións da tradición ata elaborar un imaxinario étnico.

\section{ALGÚNS EXEMPLOS DE TRADICIÓNS REINTERPRETADAS OU INVENTADAS}

Aclararemos para comezar que utilizamos aquí a idea de «reinterpretación» ou «reubicación» coma un procedemento seguido para sacar un trazo cultural calquera (unha danza, unha lenda, etc.) do seu contexto cultural e situala noutro, o que provoca a aparición dun novo significado simbólico no significante. Cando a relación entre a nova tradición e o referente orixinario é moi escasa, ou cando esta relación non existe, podemos falar dunha «invención» no sentido de creación de tradicións. Queremos advertir tamén que non usamos esta terminoloxía en sentido depectivo ou «deslexitimador». Estamos convencidos de que o proceso de reinterpretación ou mesmo de invención da tradición, malia posibles excesos, é algo necesario para a adecuación da identidade étnica e nacional ás sempre novas e cambiantes circunstancias. Non é válida para nós a argumentación xenérica de que un trazo de cultura «adulterado» ou «inauténtico» descualifica o grupo que fai uso del, pois o que se pretende nestes casos é despregar unha estratexia encamiñada non a substituír inautenticidade por autenticidade, senón a impoñer outros trazos alleos que poden frecuentemente ser cualificados tamén de «inauténticos». Sen prexuízo de que debamos de ser coidadosos na reinterpretación das tradicións, e de que certas manipulacións da cultura popular poidan resultar altamente criticables, non é desexable caer na trampa de crer que somos 
territorio de gracia do Rocío quedou cinxido por moito tempo ás marismas e algunha que outra localidade non moi distante. Cando chegamos ó século XX, prodúcese unha expansión espacial e numérica das irmandades, que eran 10 en 1900, 13 en 1920, 16 en 1930, 26 en 1940, 30 en 1950, 33 en 1960, 37 en 1970, 61 en 1980, 82 en 1990, e 90 en 1993. O constante incremento fixo que o andazo rociero se espalle por Andalucía e que ultrapase mesmo as fronteiras físicas da rexión, chegando a zonas tan arredadas coma Madrid ou Barcelona da man dos emigrantes. Mesmo os andaluces afincados en Catalunya celebran nos últimos tempos os seus propios «Rocíos», que pretenden revivir en terra allea o que é a romaría almonteña. Como di o antes citado profesor «las fechas del boom rociero no dejan lugar a dudas : éste tiene lugar a partir de los años setenta, y su impulso y desarrollo, su extensión a todas las provincias andaluzas y entre los andaluces de la emigración, coinciden plenamente con otro boom: el de la extensión y profundización del sentimiento, y parcialmente de la conciencia, de pertenencia a un pueblo y a un país específico, Andalucía» (MORENO, 1995: 139). Unha vez máis, neste caso no que se refire a unha romaría, estamos ante unha reinterpretación da tradición festiva, pasando un sinxelo santuario das marismas a ser símbolo de identidade andaluza.

Un terceiro exemplo deste labor de reinterpretación con fins identitarios podemos atopalo na mesma Galicia. Referímonos á festa de Santiago. O Apóstolo foi de sempre patrono de Galicia. Os galegos de Madrid xa se agrupaban no século XVIII arredor deste símbolo relixioso, creando a «Real Congregación del Apóstol Santiago», e no mesmo século moitos galegos que estaban na sega de Castela celebraban o 25 de xullo con festa nestas alleas terras (GONZÁLEZ REBOREDO, 1997b: 513). Pero estas celebracións tiñan unha dimensión de mero referente festivo- relixioso e non se relacionaban directamente coa reivindicación dunha identidade política galega en conxunto. Algo moi diferente sucede cando xorde no presente século un nacionalismo galego que pretende non só aproveitar trazos da historia, da lingua ou do folklore, senón tamén incorporar referentes simbólicos de gran forza. Por iso a festa acabou tendo unha dimensión identitaria e o día do señor Santiago pasou a ser, como é nos nosos días, o Día da Patria Galega gracias a unha nova significación da festividade que comezaron a potenciar os integrantes das Irmandades da Fala nos anos vinte do noso século.

"CUADERnOS DE ESTUDIOS GALLEGOS", Tomo XLVII, Fascículo 112, Santiago 2000. 
os únicos falsarios da Terra e que os outros son máis «auténticos» ca nós, pois tal idea acostuma a non ser certa. Nesta cuestión creo que debemos de ter a valentía de recoñecer a imperiosa necesidade de reinterpretar e mesmo de inventar tradicións coma único mecanismo posible para manter unha necesaria diversidade no medio da uniformidade á que nos está conducindo o mundo actual. Feita esta advertencia, pasaremos a citar unhas cantas mostras do proceso de reinterpretación e mesmo de invención das tradicións.

Un primeiro exemplo deste proceso no campo do folklore pode ser o dunha danza ben coñecida de todos : a sardana catalana. Esta manifestación cultural, de berce ampurdanés, non tiña ata avanzado o século pasado ningunha significación especial, pois era un de tantos bailes que se executaban en contextos festivos de Catalunya. Mais, a partir da $R e-$ naixença, literatos e músicos comezan a atopar nela unha virtualidade que consiste en ser a expresión dunha raza. Para $\mathrm{S}$. Rusiñol trócase en «l'esperit del nostre poble», e o historiador Pella i Forgas propoñía en 1883 que fose a danza nacional de Catalunya. Este proceso de sublimación foi acompañado dunha estandardización da danza gracias a personaxes coma un inmigrante andaluz, Pep Ventura, considerado como un dos reelaboradores da actual sardana (BRANDES, 1985: 165). Para a crecente burguesía comprometida co rexionalismo finisecular esta danza xa no será unha mera forma de divertimiento festivo labrego ou vilego, tal e como se desenvolvera orixinariamente, senón manifestación da identidade catalana. A sardana foi deste xeito reinterpretada e reubicada, pasando a ter unha nova dimensión de significado por moito que o significante formal sobrevivise (PRAT, 1988: 171). Hai que advertir de pasada que, en menor medida, tamén a nosa galega muiñeira foi elevada á categoría de danza nacional de Galicia por rexionalistas e nacionalistas, e o propio Alexandre Bóveda considerouna apropiada para cumprir este labor identitario (COSTA VÁZQUEZ- MARIÑO, 1997: 218).

Outra mostra é o dunha amplamente divulgada romaría andaluza, a do Rocío. Un dos seus estudiosos, o profesor Isidoro Moreno, ten indicado que orixinariamente o santuario do Rocío estaba vencellado á localidade de Almonte, á que pertence a irmandade rociera chamada Matriz. Nos séculos XVII e XVIII vanse crear outras irmandades nas vilas do contorno marismeño, como Villamanrique ou Pilas. Con posterioridade, no século XIX, aparecen irmandades de localidades sevillanas, pero en xeral o 
O fenómeno, como era de agardar, está amplamente documentado no resto de Europa nos dous últimos séculos. Así, o traxe popular do sur da Alemaña, segundo deixou dito no século pasado o escritor da Selva Negra Heinrich Hansjakob, é un garante do respecto á relixión, un vínculo co país natal e unha mostra de fidelidade á familia e ó patriotismo. Esta dimensión ideolóxico-identitaria é a que garantíu que esta vestimenta, máis ou menos adaptada ós novos tempos, sobrevivise. Nos salóns bávaros e austríacos foi usada dende comezos do século XIX, e na alborada do século XX consolidouse coma vestimenta propia de funcionarios en zonas de montaña, de comerciantes e de burgueses propietarios de vilas. O traxe así usado non era algo necesariamente práctico, senón unha manifestación de que se pertencía a unha tradición entendida coma amor á terra natal. A súa relación coa vida dura dos labregos bávaros ou tiroleses acabou sendo realmente superficial (BAUSINGER, 1993: 225 e 229).

Os casos aducidos poden ser unhas cantas mostras de cómo certas tradicións tomadas do campesiñado (traxe, danzas, romarías, etc.) foron sometidas a un proceso de reinterpretación e atinxiron un novo significado identitario, unha nova dimensión semántico-simbólica. Na dinamica da reinterpretación pártese do principio seguinte: os elementos que tomamos da tradición popular están aí «dende sempre», son algo así coma unha constante que procede diso que se vén chamando «a noite dos tempos». $\mathrm{O}$ folklore nutriuse dende o século pasado das teorías postas de moda polo evolucionismo e, posteriormente, polo difusionismo. Pensadores coma Spencer e etnólogos como Frazer estableceron unha evolución cultural semellante ó evolucionismo biolóxico propugnado por naturalistas coma Darwin. Do mesmo xeito que as especies animais evolucionan cara a formas máis adaptadas ó medio, tamén as comunidades humanas seguen un camiño semellante. Pero por esta mesma razón pode haber sociedades que quedan ancoradas nun estadio determinado do proceso evolutivo, e mesmo nas sociedades máis evolucionadas poden quedar reminiscencias de estadios anteriores. A idea de que as capas populares campesiñas conservan «supervivencias» do pasado, que son algo así coma fósiles viventes, xuntouse coa teoría romántica do Volksgeist, da existencia dunha «alma do pobo» que pervive inalterable na súa esencia no transcurso dos séculos. Por iso moitos folkloristas, o mesmo que algúns etnólogos, van practicar un método historicista, que, por paradoxal que pareza, será frecuentemente ahistórico. En realidade máis que detectar os posibles antecedentes 
temporais concretos para as prácticas que estudiaban, esforzaranse por demostrar que moitas tradicións proceden dunha prehistoria perdida na nebulosa dos tempos. Calquera culto cristián asociado a unha pedra, a unha fonte ou a unha planta será, dende esta perspectiva, mostra da cristianización dun lugar prehistórico de culto, e calquera festa na que se usen plantas pode ser pervivencia de vellos rituais relacionados coa vexetación. Sen prexuizo de que esta continuidade entre pasado distante e presente non se poda demostrar nalgúns casos, o certo é que estas afirmacións permitiron que os pobos de Europa asuman que teñen uns alicerces moi fondos, que conservan en definitiva unha prosapia prestixiosa pola súa antigüidade.

O estudio da tradición pode chegar a desmontar máis dunha destas asignacións. Sen saír de Galicia podemos documentar casos coma o de Santa Minia de Brión, onde se celebra nos nosos días unha sonada romaría que xunta miles de devotos e que ten a curiosa particularidade de que se centra nas reliquias dunha mártir de hai case dous mil anos. Pero en Brión non houbo, que saibamos, ningún santuario nin cristián nin pagán preexistente, pois os restos desta santa foron traídos aquí dende Roma no século pasado, permanecendo en Cádiz un tempo ata que o brionés Lois Tobío os trasladou á súa vila natal no ano 1847 (GONZÁLEZ REBOREDO, 1997: 114); calquera que acuda a esta romaría poderá apreciar unha serie de características propias de moitas outras romarías de Galicia de grande antigüidade, mais neste caso a citada noite dos tempos en canto ás orixes vese substituída por unha tradición moi recente, de século e medio exactamente.

Diversas tradicións folklóricas teñen unha orixe tan recente e unha relación tan flebe con feitos populares que podemos coincidir en parte co historiador Hobsbawn cando fala dunha invención das tradicións (HOBSBAWN, 1984: 9 e ss.). Se ata o momento nos ocupamos da reinterpretación ou da reubicación da tradición en novas esferas de significado, agora amosaremos algúns exemplos do que é o fenómeno da «invención», non sen insistir en que estas invencións soen ter moitas veces algunha relación, por pequena que sexa, con elementos tradicionais preexistentes.

O primeiro exemplo que imos ver está moi relacionado co folklore e refírese ó famoso traxe popular escocés, no que o elemento máis chamativo é o kilt ou saia elaborada co tecido chamado tartán. É ben coñecido que os escoceses, cando queren resaltar ostentosamente a súa identidade, 
visten o seu traxe tradicional e danzan ó son da gaita de fol, a pipe escocesa. Tanto para un estranxeiro coma para un escocés o kilté un simbolo que establece unha unión indisoluble co pasado, cun pasado de clans e de liberdades anterior á dominación inglesa. Pero, ¿é realmente o kilt unha herdanza directa da vestimenta dos vellos escoceses agrupados en clans?. O historiador Trevor-Roper ten feito un demorado estudio sobre a orixe da saia escocesa, dos deseños do tartán e do vencello destes deseños cos diferentes clans (TREVOR-ROPER, 1984: 25 e ss). Sería moi longo describir con detalle o proceso, que está moi ben documentado, e limitarémonos a citar algúns chanzos puntuais na construcción desta tradición seguindo o antes citado estudioso.

En principio podemos dicir que as Terras Altas de Escocia, os Highlands, foron ata o século XVII unha zona montesía cunha cultura influída pola veciña Irlanda. No século XVI non se coñece unha vestimenta tipicamente escocesa, sendo introducido neste tempo o tartán procedente de Flandes. Xa no século XVIII os escoceses vestían un manto suxeito cun cinto, agás os máis acomodados, que usaban calzas fabricadas con tartán; tampouco o deseño do tartán era utilizado de maneira xeneralizada para diferenciarse segundo a pertenza clánica. Neste contexto, trala unión de Escocia e Inglaterra, un inglés de Lancashire, Thomas Rawlinson, chegou en 1727 a un acordo con Ian MacDonell, o xefe do clan dos MacDonells en Glengarry, para aproveitar madeira dos bosques co fin de utilizala nunha fundición. Durante a súa estancia en Escocia comprobou que o manto escocés non era apto na tala das árbores e decidiu falar cun xastre dun rexemento acantonado en Inverness para que deseñase un modelo máis cómodo, que resultou a saia curta independente do manto. Esta nova prenda foi usada polo propio Rawlinson, por MacDonell e polos seus homes, difundíndose por Escocia. No ano 1778, escoceses asentados en Londres crearon a chamada «Sociedade das Terras Altas», que tiña por finalidade a preservación das tradicións dos Highlands, logrando autorización para que os escoceses usaran a súa vestimenta tradicional. A pesar de que houbo voces que chamaron a atención sobre o moderno que era o kilt, os propios gobernantes ingleses permitiron que unidades militares escocesas vestiran esta prenda e, cando o Ministerio da Guerra tratou de suprimilo en 1804, atopouse cunha seria resistencia. Escritores famosos como Walter Scott contribuíron a difundir o kilt, e, xa en 1822, con motivo da visita do rei Xurxo IV a Edimburgo, os fabricantes de tecidos produciron tartán 
diferenciado en canto ó deseño para que os clans e xefes de clan se puideran identíficar. Esta diferenciación do deseño por clans contou ademáis, coa colaboración de investigadores oportunistas, como os irmáns Allen, que publicaron un máis que dubidoso texto titulado Vestiarium Scoticum, no que se facía a descrición dos diferentes deseños de tartán das familias escocesas, obra que ampliaron en 1842 baixo o título de The costume of clans. Moi ben ilustrado, pero pragado de falsidades, este libro defendía a idea de que o traxe típico escocés dos Hihglands era un fósil da vestimenta medieval europea. A súa proposta equivalía a revitalizar un pasado glorioso do que o kilt era unha manifestación destacada. Malia numerosas críticas, os deseños clánicos do tartán acaban sendo aceptados pola Sociedade das Terras Altas de Londres, algo no que influíron outras obras da época, como dúas de James Logan tituladas The Scotish Gael e Clans of the Scottish Highlands. Todo isto foi acollido con entusiasmo polos fabricantes de tecidos, que atoparon nesta invención da tradición unha fonte de riqueza. Así parece ser que naceu o traxe típico escocés, hoxe utilizado con lexítimo orgullo por naturais de Escocia e os seus descendentes non só na terra natal, senón en lugares tan afastados como os Estados Unídos de América. Así se contribuíu á invención dun elemento de folklore que foi elevado, coma tantos outros, á categoría de símbolo de identidade étnica.

Como antes isinuamos, na invención dun trazo do folklore é posible conservar en certa medida unha pequena relación formal ou xenética con trazos culturais preexistentes, aínda que esta relación é tan secundaria que non impide considerar que estamos ante unha invención da tradición. Algún exemplo de Galicia pode axudarnos a percibir isto.

O primeiro deles é a famosa queimada. É ben sabido que moitos galegos da Galicia interior ou da Galicia da emigración rematan os seus xantares ou celebran xuntanzas festivas arredor dunha ola de barro na que se queima augardente mesturado con azucre, limón e, por veces, café. Con motivo da queimada os galegos de Madrid, de Barcelona, ou de calquera outra parte, despregan todo un imaxinario étnico no que aparecen sempre as inevitables meigas. Esconxuros redactados nos últimos tempos e postos á venda de diversas maneiras son recitados durante o proceso de elaboración da bebida, cobrando así o acto unha dimensión ritual de afirmación da solidariedade galega e de evocación dun imaxinario no que, no fondo, ninguén cre na mesma medida que crían os nosos labregos. A for- 
za do ritual é tal que xa moitos galegos e non galegos pensan que a queimada é algo indisolublemente asociado a Galicia.

Algúns investigadores achegáronse á queimada tratando de atopar as súas raíces históricas ou culturais (ALONSO DEL REAL, 1972: 74; CABANA CASTRO, 1996: 58 e ss.). Mais, en xeral, podemos dicir que o costume de queimar augardente era práctica esporádica na sociedade labrega. Neste contexto rural-tradicional a augardente facía de acompañamento dalgunha festa ou reunión e tiña unha certa sona na medicina caseira para curar catarros. O que nunca tivo é esa dimensión de evocación do imaxinario popular e de marca de identidade, e hai que chegar á década dos cincuenta do presente século para atopar referencias ó ritual da queimada tal e como hoxe o coñecemos, datas polas que tamén comezan os nosos oleiros a fabricar cacharros ad hoc para este mester. Como ten advertido Luciano García Alén, nas aldeas a queimada, de facerse, facíase nunha fonte ou tarteira calquera, pero un cacharreiro de Mondoñedo, Tito Freire, tivo en 1955 a ocorrencia de fabricar un cacharro específico para este mester, poñéndolle pés como os dos antigos potes de ferro (GARCÍA ALÉN, 1992: 77 e ss.). Círculos galegos da emigración fomentaron a celebración de queimadas colectivas e mesmo os nosos paisanos en Madrid editaron, no ano 1984, un casette no que se explican as características do ritual lúdico. Estes «queimadores» madrileños chegaron a se constituír nun club coa pretensión de difundir polo mundo esta práctica como signo de amizade e fraternidade festivas, e algúns escritores e homes de cultura galegos fomentaron a queimada dentro e fóra das nosas fronteiras (VÁZQUEZ VARELA,s./a.: voz «queimada»). Coma no caso do kilt escocés antes citado, semella que son os galegos emigrados os que contribúen de maneira importante a elevar a queimada á categoría de símbolo de identidade, algo que está lonxe do uso orixinario dado a esta bebida nas nosas aldeas. E isto sucede porque os emigrantes dos grupos étnicos tenden sempre a apropiarse dalgúns compoñentes da súa cultura de oríxe, construíndo así pouco a pouco o que se ven chamando unha etnicidade simbólica (EDWARDS, 1993: 227). O uso simbólico de certos aspectos da cultura é algo que vimos documentando no noso discurso, mais neste caso atopámonos con xentes que na súa vida ordinaria se desenvolven nun contexto diferente do orixinario e tan só poden conservar algún trazo da cultura con dimensión simbólica, ou tamén inventar unha tradición a partir de elementos nativos que ata entón eran secundarios ou irrelevantes como marca de identidade.

"CUADERNOS DE ESTUDIOS GALLEGOS", Tomo XLVII, Fascículo 112, Santiago 2000. 
Mais o proceso de invención de tradicións está documentado tamén dentro da propia Galicia rural, algo que exemplificaremos brevemente a continuación. É ben sabido que nos últimos decenios tivo unha ampla divulgación o Entroido celebrado en terras de Ourense. O chamado triángulo de Laza-Verín- Xinzo de Limia, coas súas características máscaras de peliqueiros, cigarróns e pantallas foi atraendo nos anos setenta e oitenta a un numeroso público que buscaba neste Entroido referentes de identidade galega ou trazos de enxebrismo. Co tempo foron renacendo outros Entroidos na mesma zona (centro-oriente de Ourense), ata o punto de que hoxe o triángulo tende a se converter nun polígono con máis lados cada vez. Pois ben, gracias ó señor Arteaga, un limiano defensor destas tradicións, puidemos saber que nunha localidade da Limia tratouse de revitalizar o Entroido hai cinco anos resucitando unhas antigas máscaras só lembradas polos vellos, chamadas vergalleiros. O problema era definir con claridade -e sen renunciar a unha vistosidade-cómo era a vestimenta do vergalleiro, cousa que non debeu de ser doada, pois recurreuse a que unha deseñadora de Ourense elaborara un modelo a partir de datos fragmentarios e tamén de máscaras de Xinzo e de Verín. O resultado é que nos últimos anos percorren as rúas da vila capital do concello estes novos vergalleiros e que a xente do lugar está plenamente identificada con esta máscara, considerada coma propia da localidade «dende sempre».

\section{DE QUEN APREDEMOS OS FILLOS DE GALICIA A SER GALEGOS E CAL PODE SER O FUTURO DA NOSA IDENTIDADE ÉTNICA}

Nos apartados anteriores tratamos de dar unha visión antropolóxica do que é unha identidade étnica. Tamén vimos que os elementos utilizados na afirmación desta identidade, exemplificados co folklore, son froito dunha recontextualización ou mesmo dunha invención que traen coma consecuencia a elevación de trazos dunha cultura rural á categoría de símbolos de etnicidade. Os datos que manexamos proceden de distintos grupos étnicos europeos, dende Laponia a Galicia, algo que fixemos intencionalmente para que se apreciase que os fenómenos descritos non son exclusivos da nosa terra, senón que están presentes en todo o continente. Pero agora temos que reorientar a nosa exposición dedicando unha última 
parte do discurso a un feito que está, así mesmo, ben documentado. Referímonos a que nos dous últimos séculos, coincidindo co desenvolvemento da civilización contemporánea, houbo un feixe de saberes e de homes que se esforzaron por xuntar un corpus de coñecementos gracias ós que todos aprendemos a ser galegos. En varios escritos témonos ocupado deste asunto (GONZÁLEZ REBOREDO, 1996,-1996b, 707 e ss.- e 1997b, no prelo) e agora achegarémonos sinopticamente ó mesmo.

Un feito amplamente coñecido é que, dende o século XIX -con antecedentes no anterior gracias a figuras coma Sarmiento- xorde en Galicia un interese pola nosa identidade, o mesmo que estaba a suceder noutras terras segundo exemplos antes aducidos. Os investigadores decimonónicos partiron do principio de que os galegos posuímos un territorio definido no que se construiu unha cultura diferenciada, da que eran boa mostra tres compoñentes : unha historia propia, unha lingua e unha tradición popular oral. Preocupación moi característica da época foi a de relacionar estes elementos cunha raza determinada, que acabou sendo a raza celta. $O$ mito das oríxes celtas do pobo galego, creado inicialmente por Verea y Aguiar, foi asumido por diversos investigadores, dende Murguía ata os homes do Seminario de Estudos Galegos no noso século (CALO LOURIDO, 1996: 20 e ss.). Aínda que a Sociedade "El Folklore Gallego», fundada na Coruña por Dona Emilia Pardo Bazán a instancias de Machado y Álvarez en 1883, tiña un programa aséptico, baseado na recollida ordenada de textos e prácticas da tradición oral, axiña os materiais recompilados por folkloristas coma Saco y Arce, Marcial Valladares, Ballesteros, o propio Murguía, Federico Maciñeira,etc. foron aproveitados para elaborar unha teoría da diferencia, é dicir, unha teoría da identidade. Grupos de intelectuais e xentes de vilas ou cidades, o mesmo que en Noruega, na Alemaña, en Escocia ou en calquera curruncho de Europa, comezaron a sentirse membros dunha comunidade diferenciada porque coñecían e gozaban con eses sinais identitarios. A carón dos estudiosos, houbo tamén galegos coma Perfecto Feijoo que se preocuparon por levar ós escenarios a vestimenta tradicional, os cantares do pobo, ou as súas danzas, e máis tarde, xa no noso século, este labor foi continuado polos membros da $\mathrm{Xe}$ ración Nós e o Seminario de Estudos Galegos, e tamén, na práctica do folklore, por moitas asociacións ou agrupacións xurdidas en vilas e cidades. Nun esforzo intelectual inxente, poñendo o seu saber e a súa imaxinación creativa ó servicio de Galicia, estes etnólogos e folkloristas, dos 
que nos podemos sentir herdeiros lexítimos neste estricto campo, foron construíndo todo un imaxinario étnico a partir dos materiais que recopilaban, foron literalmente inventando creativamente unha identidade galega (GONZÁLEZ REBOREDO, 1990: 213). Este labor é tanto máis meritorio en canto foi realizado en momentos nos que estaba medrando por todas partes outro tipo de identidade, que poderiamos calificar de cívica, e que era a que se potenciaba dende os Estados contemporáneos, entre eles o español. Malia que a emerxencia dun civismo galego, de dimensión claramente política, viu coutada a súa alborada coa Guerra Civil, resulta necesario destacar que o esforzo por manter cando menos alguns símbolos de identidade étnica non desapareceu de todo. Gracias a moitos homes e mulleres, nacionalistas, rexionalistas ou sinxelamente galegos, seguimos hoxe mantendo unha serie de trazos diferenciadores e neste sentido é no que hai que interpretar as miñas verbas anteriores de que gracias a todos eles os habitantes de Galicia aprendemos a ser galegos. Dentro da Antropoloxía académica hai unha certa tendencia a considerar o Folklore como un tipo de saber con escaso estatus científico porque o seu discurso é basicamente un discurso localista, baseado na identidade e contraposto a un discurso antropolóxico máis universalista e con sólidos enfoques teórico- metodolóxicos (PRAT, 1991: 13 e ss.). Non negaremos que o folklorismo tivo serias limitacións polo seu localismo, e tampouco deixaremos de recoñecer que esta ciencia se puxo por veces ó servicio de idearios diversos; pero hai que salientar esa débeda contraída cos seus cultivadores, que nos facilitaron materiais que serven de soporte, xunto coa lingua, a historia e o territorio, dunha identidade galega, dun imaxinario étniconacional, sen a cal hoxe seriamos pouco coma pobo.

Coma antropólogos e folkloristas non nos corresponde poñer capitán neste barco que se chama Galicia. As nosas xentes contan con canles, mellores ou peores, para manifestar a súa vontade neste sentido. Pero é evidente que o noso labor, queréndoo ou sen querelo, contribúe a crear unha conciencia identitaria na tripulación, é dicir, no pobo galego. Unha conciencia identitaria que debe ser pacífica e dialogante, pero que ten diante de si algúns retos ós que haberá que enfrontarse no futuro. Un deles será o de dar resposta axeitada ás consecuencias da catástrofe demográfica na que caeu Galicia, provocando que na segunda metade do século XXI serán poucos os galegos que poidan construír a súa xenealoxía a partir de nós, é dicir, que imos ter moi poucos homes e mulleres ós que

"CUADERNOS DE ESTUdiOS GALLEGOS", Tomo XLVII, Fascículo 112, Santiago 2000. 
transmitir ese legado elaborado con tanto esforzo e imaxinación. Os baleiros producidos por esta quebra demográfica van ser ocupados, como xa está sucedendo noutras terras de Europa, por xentes pertencentes a outros grupos étnicos, ás veces moi distanciados de nós. Estamos avocados, con máis retardo que noutras partes pero con seguridade, a nos converter nunha sociedade multiétnica. E nesa situación, ¿seremos capaces de manter a nosa galeguidade adaptándoa ás novas circunstancias?; ¿ou quizais poderemos subsumir na nosa identidade a xentes procedentes de identidades alleas?... A resposta a estas cuestións non é doada, pero o noso futuro coma pobo depende da capacidade que teñamos para resolver con acerto este dilema. Quero facer constar que esta inquedanza que manifesto non está inspirada en ningunha opción ideolóxica nin racista nin conservadora intransixente. Outros seres humanos estanse a facer as mesmas preguntas, e valla coma mostra a insistencia no asunto entre os analistas que falan ou escriben dos franco-canadenses, é dicir, os québecquois, os que ven como Québec camiña inexorablemente cara a unha configuración multiétnica e multicultural. Así, Dansereau facía esta pregunta dramática nun artigo publicado no xornal Le Devoir en 1987: «¿Que debemos facer nós para integrar os inmigrantes sen asimilalos pero sen perdernos?» (cit. por BRETON, 1993: 355); e Beaucage apunta nun recente escrito que no seo do mesmo Québec teñen que xurdir novas formas de ser québécquois aceptadas tanto polos francófonos coma polos anglos, os indíxenas e os inmigrantes (BEAUCAGE, 1993: 241). En realidade, o nacionalismo quebequés construiuse nos últimos decenios coma unha reacción ante a crise de dous puntais da identidade franco-canadense, ademáis da lingua: a relixión católica e a alta natalidade que garantía non só a reproducción biolóxica, senón tamén a cultural (HOBSBAWN, 1998: 181-182). E esta quebra obriga a unha necesaria redefinición das fronteiras étnicas e nacionais e a unha reformulación para o futuro da identidade franco-canadense. Seguramente os galegos -coma os québecquois, os casteláns, os escoceses ou coma calquera pobo que queira sobrevivir diferenciado- teremos que facer novos esforzos para chegar a unha inmersión da nosa identidade étnica nunha identidade cívica na que teña cabida a pluralidade, a ser posible sen traumatismos, pero carecemos polo momento de suficiente perspectiva para saber cómo se desenvolverá o proceso ou cales serán as redefinicións da identidade ás que dará lugar. En calquera caso é preciso que nos poñamos a reflexionar sobre o asunto, e que o fagan ta-

"CUADERNOS DE ESTUdiOS GALLEGOS", Tomo XLVII, Fascículo 112, Santiago 2000. 
mén as forzas políticas e sociáis, aínda a custa de sacrificar logros inmediatos ou revisar puntos programáticos.

Insinuamos anteriormente un reto ó que Galicia se terá que enfrontar nun futuro máis ou menos distante. Pero non hai que esquecer que a máis curto prazo verémonos obrigados a enfrontar outro, tal o de redefinir as nosas fronteiras étnicas (e refírome unha vez máis ás fronteiras mentais máis que ás físicas) en función da nosa integración na Unión Europea. Os Estados contemporáneos, ó longo do seu tempo de xénese e consolidación, elaboraron toda unha teoría dos límites nacionais, rexionais ou mesmo provinciais que foi traducida en mapas e que incidiu decisivamente no deseño das fronteiras mentais dos seres humanos. O mapa, ó que aluden algúns antropólogos nos seus estudios, converteuse nunha representación metafórica dos países con clara vocación simbólica. O feito de que en tódolos mapas mundiais Europa apareza na parte central non produce consecuencias pouco inocentes, como dí Eriksen (ERIKSEN, 1993:106); e pode ser inocente na súa plasmación inicial, mais non nos seus resultados na mentalidade da xente, que en moitos mapas escolares se represente soamente a parte da Península Ibérica que corresponde a España, suprimindo en contra de toda lóxica natural o espacio ocupado por Portugal. As referencias escritas, os discursos e especialmente os mapas dunha sociedade escolarizada son potentes xeradores de identidade étnica e cívica, son receptáculos abstractos nos que situamos crenzas, valores, vínculos e tamén prácticas folklóricas (por iso o Estado, é dicir, o poder de calquera signo, ten tanto interese en presentalos á súa maneira); gracias en boa parte á súa maxia as fronteiras físicas acaban trocándose en sagradas fronteiras, como diría o antropólogo J. Mira (MIRA, 1990: 36-37). Pero na actualidade esta construcción de fronteiras está entrando nunha dinámica lenta, mais irreversible, de redefinición, e nesa dinámica tamén teremos que reformar as nosas pautas de interacción cos outros, é dicir, verémonos obrigados a renegociar os nosos límites étnicos, recolocando ós «outros» nos nosos mapas cognitivos por unha banda e recolocándonos nós mesmos nos elaborados por eles. Temos, pois, tamén neste campo outro reto que se manifesta polo momento como unha incógnita. ¿Que lugar ocuparán os nosos actuais sinais de identidade nestes novos contextos?, ¿seremos capaces de nos inserir nese novo universo sen perdelas?, ¿a que teremos que renunciar, qué cousas poderemos salvar e qué outras non teremos máis remedio que asumir? ¿quedarémonos, nun proceso de simplifica-

"CUADERNOS DE ESTUdiOS GALLEGOS", Tomo XLVII, Fascículo 112, Santiago 2000. 
ción que equivale a empobrecimento da identidade, nunha defensa a ultranza da lingua coma trazo diferencial e renunciaremos a outras peculiaridades propias de diversos ámbitos da cultura (prácticas relixiosas, hábitos alimenticios, concepcións da festa,etc.)? De novo as preguntas asaltan a mente do antropólogo sen atopar unha resposta clara. En calquera caso a propia Antropoloxía elaborou algunha insinuación que paso a apuntar antes de rematar a miña reflexión.

Hai xa anos que un antropólogo americano, Spicer, enumerou unha serie de indicadores que, de cumprirse maioritariamente, dan lugar ó que el chamou «pobos perdurables». A conciencia firme de posuír unha terra de referencia, ou unha lingua e uns costumes compartidos, son algunhas desas condicións. Baseándose nisto, podemos incluír entre os pobos persistentes a pobos coma os cataláns, os xudeus, os galeses, os indios hopi e outros, entre eles o galego (cit. por DUNDES, 1983: 239; e por BRANDES, 1993: 31-33). Eu, pola miña parte, comparto esta perspectiva optimista, aínda que advirto que estes compoñentes da persistencia poden chegar a un deterioro irreversible se non van acompañados de dúas condicións engadidas que eu calificaría de firmeza na identidade e de capacidade de redefinición e recreación da identidade. Segundo sinalan algúns estudiosos do nacionalismo, non tódalas culturas da Terra poderán chegar a desenvolver un nacionalismo propio; de feito Gellner indica, tomando coma referencia a lingua, que hai no mundo arredor de 8000 grupos étnicos, pero soamente, como máximo, uns 800 nacionalismos máis ou menos vigorosos (GELLNER, 1997: 65-66); e iso é indicio de que moitos grupos humanos están condenados a quedar absorvidos dentro de Estados hexemónicos, e que outros verán reducida a súa identidade a escuálidos trazos diferenciais que non permitirán o mantemento dunha identidade nacional. Que o pobo galego é un pobo persistente penso que está fóra de toda dúbida. Pero se non engadimos firmeza e imaxinación, é dicir, vontade de supervivencia á nosa identidade, corremos o risco de que esta se reduza ou mesmo desapareza. Como diría o poeta Celso Emilio Ferreiro, nesta situación quedariámonos sen pobo, o que equivale a quedarnos sen patria. Firmeza e creatividade que, por suposto, non teñen por que implicar agresión nin fundamentalismo, senón capacidade de interacción baseada na vontade de sobrevivir na diversidade mediante a negociación permanente e simétrica co «outro».

"CUADERNOS DE ESTUDIOS GALLEGOS", Tomo XLVII, Fascículo 112, Santiago 2000. 


\section{BIBLIOGRAFÍA}

A. AGUIRRE (ed.): 1993. Diccionario temático de Antropología. $2^{\mathrm{a}}$ edición. Ed. Boixareu. Barcelona.

C. ALONSO DEL REAL: 1972 «As oríxes da queimada». Grial, $\mathrm{n}^{\circ} 35$. Vigo. Páx. 74 e ss.

F. BARTH: 1976. «Introducción». En Los grupos étnicos y sus fronteras. Ed. Fondo de Cultura Económica. México. Páx. 9 e ss.

H. BAUSINGER: 1993. "Volkskunde» ou l'ethnologie allemande. Éditions de la maison des sciences de l'homme. París.

P. BEAUCAGE: 1993. «Ser quebequense en Canadá, ¿es posible en 1992?». En R. ÁVILA PALAFOX/T. CALVO BUEZAS : Identidades nacionalismos y regiones. Ed. Univ. de Guadalajara/Universidad Complutense. Madrid. Páx. 225 e ss.

P. BONTÉ /M. IZARD (Dirs.): 1996. Diccionario de Etnología y Antropología. Ed. Akal. Madrid.

S. BRANDES: 1985. «La sardana como símbolo nacional catalán». Revista de Folklore. no 59, tomo 5. Valladolid. Páx. 162 e ss.

S. BRANDES: 1993. «Estudio antropolóxico das fronteiras: problemas e perspectivas». En Actas do Simposio de Antropoloxía "Lindeiros da Galeguidade II» Ed. Consello da Cultura Galega. Santiago. Páx. 27 e ss.

R. BRETON: 1993. «From Ethnic to Civic Nationalism: English Canadá and Québec». En J. HUTCHINSON /A. D SMITH: Ethnicity. Oxford University Press. Oxford-New York. Páx. 348 e ss.

M. CABADA CASTRO: 1996. «Da anterga sacralización do lume ó actual ritual da queimada». Grial. Vigo. Tomo XXXIV, nº 129. Páx. 43 e ss.

"CUADERNOS DE ESTUdIOS GALLEGOS", Tomo XLVII, Fascículo 112, Santiago 2000. 
F. CALO LOURIDO: 1996. «Les inventeurs d'une Galice celte». Revista ArMen. Douarnenez. № 79 , páx. 20 e ss.

L. COSTA VÁZQUEZ-MARIÑO: 1997. «O baile tradicional en Galicia: procesos de folklorización». Boletín Auriense. Tomo XXVI. Ourense. Páx. 213 e ss.

A. DUNDES: 1983. «Definig Identity through Folklore». En A. JACOBSON-WIDDING (ed.): Identity: Personal and Socio-cultural. Almquist and Wiksell International / Humanities Press Inc. Stockholm /Atlantic Highlands, N.J., USA. Páx. 235 e ss.

J. EDWARDS: 1996. «Symbolic Ethnicity and Language». En J. HUTCHINSON/ A. D. SMITH: Ethnicity. Oxford University Press. Oxford-New York. Páx. 227 e ss.

H. EIDHEIM: 1976. «Cuando la identidad étnica es un estigma social». En BARTH: Los grupos étnicos y sus fronteras. Ed. Fondo de Cultura Económica. México. Páx. 50 e ss.

T. H. ERIKSEN: 1993. Ethnicity and Nationalism. Pluto Press. LondonBoulder, Colorado.

C. ESTEVA FABREGAT: 1984. Estado, etnicidad y bicluturalismo. Ed. Península. Barcelona.

L. GARCIA ALÉN: 1992. O señor das olas. Crónicas de viaxes e outras historias. Ed. El Correo Gallego. Santiago.

C. GEERTZ: 1988. La interpretación de las culturas. Gedisa Editorial. Barcelona.

E. GELLNER: 1997. Naciones y nacionalismo. Alianza Universidad. Madrid.

X. M. GONZÁLEZ REBOREDO: s./ a. «Folklore». En Gran Enciclopedia Gallega. Silverio Cañada Ed. Gijón.

"CUADERNOS DE ESTUdios GALLEGOS", Tomo XLVII, Fascículo 112, Santiago 2000. 
X. M. GONZÁLEZ REBOREDO: 1990. «Elementos de identidade nos historiadores e etnógrafos galegos da primeira metade do século XX». En Actas do Simposio Internacional de Antropoloxía "Identidade e Territorio». Ed. Consello da Cultura Galega. Santiago. Páx. 215 e ss.

X. M. GONZÁLEZ REBOREDO: 1996. La construcción del texto etnográfico a través de dos autores. Aportación a una historia de la Etnografia en Galicia. Ed. Instituto de Estudios Gallegos «P. Sarmiento» (CSIC). Santiago.

X. M. GONZÁLEZ REBOREDO: 1996 b. «Notas para una historia de la Antropologia en Galicia». En Identidad y fronteras culturales: Antropología y museística. Actas II Congreso de Historia de la Antropología y Antropología Aplicada. Ed. Asociación de Psicología de Extremadura. Badajoz. Páx. 707 e ss.

X. M. GONZÁLEZ REBOREDO: 1997. Guía de festas populares de Galicia. Ed. Galaxia. Vigo.

X. M. GONZÁLEZ REBOREDO: 1997b. «Aproximación á identidade do emigrante gallego»e «Historia dos estudios de cultura tradicional en Galicia. Do nacimento do folklore ós nosos días» En Proxecto $G a-$ licia. Antropoloxía Cultural. Hércules de Ediciones, A Coruña. Tomo XXVI, páx. 493 e ss., e tomo XXIX (no prelo).

E. HOBSBAWN: 1984. «Introduçâo: a invençâo das tradiçôes». En $A$ invençâo das tradiçôes. Ed. Paz e Terra. Río de Janeiro. Páx. 9 e ss.

E. HOBSBAWN: 1998. Naciones y nacionalismo desde 1780. Ed. Crítica. Barcelona ( $2^{\mathrm{a}} \mathrm{Ed}$.).

J. HUTCHINSON / A. D. SMITH: 1996. «Introduction». En Ethnicity. Oxford University Press. Oxford-New York. Páx. 3 e ss.

J. KREJCI / V. VELÍMSKÝ: 1996. «Ethnic and Political Nations in Europe». En J. HUTCHINSON/A. D. SMITH: Ethnicity. Oxford University Press. Oxford- New York. Páx. 209 e ss. 
J. MARTÍ: 1996. El folklorismo. Uso y abuso de la tradición.Ed. Ronsel, Barcelona.

J. MIRA: 1990. «La sagrada frontera». En Actas do Simposio Internacional de Antropoloxía «Identidade e Territorio». Ed. Consello da Cultura Galega. Santiago. Páx. 29 e ss.

I. MORENO NAVARRO: 1995. «El Rocío: de romería de las marismas a fiesta de identidad andaluza». En Actas do simposio de Antropoloxía «Romarías e peregrinacións». Ed. Consello da Cultura Galega. Santiago. Páx. 121 e ss.

J. PRAT: 1988. «Mites i estereotips de la identitat (taula rodona)». En Encontre d'Antropología i Diversitat Hispánica. Generalitat de Catalunya- Departament de Cultura. Barcelona. Páx. 169 e ss.

J. PRAT : 1991. «Historia. Estudio introductorio». En VVAA: Antropología de los pueblos de España. Ed. Taurus. Madrid. Páx. 13 e ss.

J. J. PUJADAS : 1993. Etnicidad. Identidad cultural de los pueblos. Eudema. Madrid.

E. TONKIN / M. McDONALD / M. CHAPMAN : 1996. «History and Ethnicity». En J. HUTCHINSON/A. SMITH(eds.): Ethnicity. Oxford University Press. Oxford-New York. Páx. 18 e ss.

F. TÖNNIES: 1979. Comunidad y asociación. Ed. Península. Barcelona.

H. TREVOR-ROPER : 1984. «A invençâo das tradiçôes: a tradiçâo das Terras Altas (Highlands) da Escócia». En E. HOBSBAWN /T. RANGER: A invençâo das Tradiçôes. Ed. Paz e Terra. Río de Janeiro. Páx. 25 e ss.

V. W. TURNER: 1993. «Pasos, márgenes y pobreza: símbolos religiosos de la communitas». En P. BOHANNAN/ M. GLAZER: Antropología. Lecturas ( $2^{\mathrm{a}}$ ed.). Ed. McGraw-Hill. Madrid. Páx. 517 e ss.

"CUADERNOS DE ESTUdIOS GALLEGOS", Tomo XLVII, Fascículo 112, Santiago 2000. 
J. M. VÁZQUEZ VARELA: S./a. «Queimada». Gran Enciclopedia Gallega. Silverio Cañada Ed. Gijón.

H. VELASCO / F. CRUCES / A. DÍAZ DE RADA: 1996. «Fiestas de todos, fiestas para todos». Antropología. Revista de pensamiento antropológico y estudios etnográficos. Madrid. № 11, páx.147 e ss. 